DOI: https://doi.org/10.47405/mjssh.v5i8.460

\begin{tabular}{|c|c|}
\hline sis & Malaysian Journal of Social Sciences and Humanities (MJSSH) \\
\hline Malaysian Journal of & Volume 5, Issue 8, August 2020 \\
\hline $\begin{array}{l}\text { Humantitis } \\
\text { (MJ - SSH) }\end{array}$ & e-ISSN : 2504-8562 \\
\hline & $\begin{array}{l}\text { Journal home page: } \\
\text { www.msocialsciences.com }\end{array}$ \\
\hline
\end{tabular}

\title{
Information, Motivation and Behavioural Factors in Influencing Diabetes Self-Care: A Conceptual Paper
}

\author{
Albeny Joslyn Panting1, Tengku Puteri Nadiah Tengku Baharudin Shah', Nurul Nadhirah Nasir', Nur \\ Izzati Mohammed Nadzri1, Nadia Amirudin', Norbaidurah Ithnain'1, Saiful Adli Suhaimi' ${ }^{1}$, Rosnani \\ Kassim ${ }^{1}$, Manimaran Krishnan' ${ }^{1}$ \\ 1Institute for Health Behavioural Research, National Institute of Health, Ministry of Health, Malaysia
}

Correspondence: Albeny Joslyn Panting (kongsi007@gmail.com)

\begin{abstract}
Globally, diabetes is a major public health concern and has impacted an estimated 425 million adults. The increasing trend of diabetes incidence has impacted the Malaysian population and healthcare system. Evidence from studies suggested that diabetes can be treated and controlled through behavioural intervention. These include combining lifestyle with pharmacotherapy. Scholars in health behaviour highlighted the importance of assessing and monitoring the behavioural intervention among diabetic patients in terms of psychosocial aspects, such as information, motivation and behavioural factors, in relations with diabetes self-care. This article provides an overview of the empirical evidence regarding the importance of identifying information, motivation and behavioural factors, in relations with diabetes self-care. Information is among the prominent factors in establishing good diabetes management. Motivation can be conceptually defined as factors that predispose one to action and cues to behaviour change. Behavioural factors identified in this review includes compliance towards diabetes self-care. The outcome of this review could provide a better understanding of information, motivation and behavioural factors, and its relations with diabetes self-care.
\end{abstract}

Keywords: diabetes self-care, information, motivation, behavioural, type 2 diabetes mellitus

\section{Introduction}

Diabetes Mellitus (DM) is a chronic disease that occurs either when the pancreas does not produce enough insulin or when the body cannot effectively use the insulin it produces (World Health Organisation [WHO], 2016). A large proportion of diabetic patients are overweight and have a combination of insulin resistance and impaired insulin secretion, and these particular patients increased substantially in the past three to four decades (Polonsky, 2012).

Thus, the American Diabetes Association (ADA) (2013) suggested that apart from required continuous medical care and regular access to support systems, diabetic patients need other behavioural interventions, such as diabetes education, self-management and social support from caregivers like family members, peers and friends. With regard to the importance of behavioural intervention in controlling diabetes, Aljasem, Peyrot, Wissow and Rubin (2001) highlighted how Diabetes Self-Care (DSC) functions in treatment and control of the disease. The authors defined DSC as the "degree to which one adopts a healthy lifestyle and takes prescribed medications and behaviours that allow 
persons with diabetes to manage their blood glucose by monitoring glucose levels and altering diet and medications in response to or anticipation of blood glucose variations" (Aljasem et al., 2001, p.397).

Globally, DM is a major public health concern and has impacted an estimated 425 million adult population (Sathish, 2019). Of this number, almost three-quarters of the diabetic patients live in low and middle-income countries with an estimated economic implication amounting in the trillions of US dollars.

Malaysia has the highest prevalence of DM among countries in Asia and among the highest in the world with an estimated 3.6 million cases. This number is expected to increase to 7 million by 2025 (Chatterjee, Khunti, \& Davies, 2017). The magnitude of DM can be seen from a series of data from the National Health and Morbidity Survey (NHMS) that shows an increasing trend; 2011 (11.2 percent), 2015 (13.4 percent) and 2019 (18.3 percent) respectively (Institute for Public Health, NHMS, 2019). DM has been rising more rapidly in Malaysia with the prevalence of this disease varying among the major ethnic groups in Malaysia; Indians have the highest prevalence of T2DM, followed by Malays and Chinese (NHMS, 2019; Hussein, Taher, Singh \& Swee, 2015). The increasing trend of prevalence of DM has impacted the Malaysian population and healthcare system (International Diabetes Federation [IDF], 2020). Hence, these data show that DM is a major public health concern and requires more significant attention.

In general, behavioural changes or modifications in DSC involve eating healthy, being physically active and avoiding smoking. This can be seen in several empirical evidences from studies conducted on the impact of lifestyle modifications on DSC. Among these is the study by Gillespie \& Lenz (2011), which indicates that 90 percent of Type 2 Diabetes Mellitus (T2DM), 80 percent of coronary artery disease and 70 percent of all strokes are potentially preventable by some forms of behavioural change elements, such as a combination of not smoking, maintaining a healthy bodyweight, regular physical activity, healthy eating habits and alcohol consumption.

Any behavioural intervention that incorporates behavioural change strategy requires a behavioural diagnosis in the beginning of implementation (Bartlett, 1982). The behavioural diagnosis is defined as an assessment of influences on the desired patient behaviour, which includes consideration of individual, social, environmental and medical regimen factors that may either impede or facilitate behaviour (Bartlett, 1982).

Additionally, the need to investigate or "diagnose" the patient's behaviour is based on several behavioural change theories including Health Belief Model (Janz and Becker, 1984); Social Cognitive Theory (Bandura, 1986); Theory of Planned Behaviour (Ajzen \& Driver, 1991) and Self-Regulation Theory (Carver \& Scheier, 1998). The application of these theories aimed to change behaviour among diabetic patients. These theories can be categorised into four main domains; motivators, inhibitors/facilitators, intentions, and triggers. Theoretically, the interactions between these behavioural domains can be seen in the patient-centred approach or patient empowerment in diabetes management, which suggests that the patient is at the centre of the behaviour change process. The patient must implement DSC (and therefore must be amenable to proposed changes), and the patient must be internally motivated to change (Peyrot \& Rubin, 2007). Furthermore, Fishbein (2008) highlighted the importance of assessing and monitoring of behaviour modification among diabetic patients in terms of psychosocial aspects, such as information, motivation and behavioural (IMB) factors, as well as clinical biomarkers.

However, to the best of our knowledge, there are limited studies on IMB factors in complying with DSC, especially in Malaysia. Thus, the main purpose of this review is to explore evidence regarding IMB related factors in DSC. This review also highlighted the importance of behavioural intervention in a diabetic patient's management, particularly in behavioural changes. The outcome of this review could guide future research and provide a better understanding of IMB and its relationship to effective DSC. Based on the after mentioned argument, this review discussed three prominent factors that influenced DSC; information, motivation and behaviour. 


\section{Information}

In terms of DSC, information is among the prominent factors in establishing a recommended diabetes management. Numerous studies suggested that the main source of information was obtained from health care educators (Rahaman, Majdzadeh, Naieni, \& Raza, 2017; Mukhopadhyay, Paul, Das, Sengupta, \& Majumder, 2010; Karimy, Koohestani, \& Araban, 2018). Besides, the media (i.e. internet, radio, television and newspaper) was also a main source of health information for patients (G. B. Rathod, S. Rathod, Parmar, \& Parikh, 2014).

Results related to the level of a patient's knowledge on diabetes were varies. A study by Solanki, Sheth, Shah, \& Mehta (2017) revealed that the patients were unaware of their insulin level, which may have led to misinterpretation the insulin as harmful. The authors further found that patients believed diabetes can be cured, and more than half of the patients considered diabetes to be curable by consuming bitter food. In addition, knowledge misperception on diet is observed, where respondents considered fast food as healthy food (Saleh et al., 2012a). A majority of the respondents in the study did not know the normal level of blood glucose. Other findings by Mohammadi, Karim, Talib and Amani (2015) and Nagar et al. (2018) revealed that patients misinterpreted the characteristics of diabetes by higher glucose level.

The lack of information may have contributed to non-compliant behaviour in diabetic patients. Bains and Egede (2011) highlighted lack of knowledge among health care providers (HCP) attributed to information gap. The study also highlighted problems related to an ineffective approach in delivering information to patients. Several studies suggested a better approach in disseminating diabetes information by adapting to certain population needs; for instance, using local language and common analogies (Ahmad, Ramadas, Fatt, \& Zain, 2014; Kueh \& Kuan, 2018).

Another important issue related to information gap in DSC is the availability and accessibility to the health care services. According to $\mathrm{Wu}$ et al. (2011) and Upadhyay, Izham, Alurkar, Mishra, and Palaian (2012), lack of proper teaching facilities for diabetes intervention in health facilities contributed to patient's lack of knowledge on diabetes. Irregular follow-up with health personnel also added to patients' poor knowledge on diabetes as compared to those who frequently followed up with HCPs (Ahmad et al., 2014). Information gap regarding DSC was not only affected by diabetes-related information deficit but also by diabetic patients' misinformation regarding the usage of alternative medication, such as Ayurveda, homeopathy and consulting spiritual healers that they perceived could cure or treat diabetes (Wu et al., 2011; Nazir, Hassali, Saleem, Bashir, \& Aljadhey, 2016).

Race also associated with diabetes-related knowledge, especially among the low-income population (Bains \& Egede, 2011). Studies by Nagar et al. (2018) and Islam et al. (2015) showed the impact of gender on diabetes-related knowledge in which male patients scored higher in knowledge than females. Patients who had family history with diabetes were more knowledgeable about diabetes (Shrestha et al., 2015). Additionally, location also played an important factor in determining a respondent's knowledge whereby those living in the rural areas had limited access to diabetes health related information compared to those living in the urban areas (Islam et al., 2015).

Literatures suggested some potential strategies to improve DSC by comprehensive health communication approach (Lalazaryan \& Zare-Farashbandi, 2014). For example, providing personalised patients' education on diabetes (Burke, Sherr, \& Lipman, 2014), focus on specific methods to educate, inform and influence patients' information seeking behaviour. Furthermore, clinical evidence suggested mobile phones could potentially benefit in diabetes interventions, particularly for SelfMonitoring Blood Glucose (SMBG), especially in facilitating patients' empowerment, awareness and behavioural change (Istepanian, 2015). Apart from that, the roles of telehealth (i.e. interactive video call) in providing specialised individual support for diabetic patients, particularly in enhancing the quality of DSC were recommended (Duke et al., 2018). 


\section{Motivation}

The second prominent factor reviewed in this paper is motivation. According to Peyrot and Rubin (2007) motivation can be defined in the context of behavioural theories in four perspectives. First, motivation can be defined as factor that predispose one to action in the form of perceived need, perceived benefits, outcome expectancies, rewards /incentives and cues to action. Second, motivation referred as resources for action as prerequisites to action (i.e. resources such as funds, skills or support). Third, motivation in the form of intentions which are an important proximal cause of behaviour change; for instance, diabetic patients must have the intention to change their dietary habit, be ready to change in the present, and have an achievable and practical goal. Lastly, motivation can be seen as triggers that shift an individual from being predisposed to action into an action state.

There are vast publications highlighted on the relationship of motivation and DSC in terms of compliance to medication, diet and SMBG. Numerous studies highlighted how motivation by means of personal attitude towards engaging behaviour was more favourable, specifically in dietary modification (Saleh, Mumu, Ara, Begum, \& Ali, 2012b; Hawal, Shivaswamy, Kambar, Patil, \& Hiremath, 2012). Several other studies found a majority of respondents with a positive attitude towards importance of care in terms of medication and control of blood glucose level (Al-Maskari et al., 2013; Hawal et al., 2012). Additionally, those who regularly monitor their glucose level seem to be self-motivated and this might increase their awareness on diabetes (Zareban, Karimy, Niknami, Haidarnia, \& Rakhshani, 2014).

Apart from self-motivation, social motivation promotes critical influence towards a patient's self-care. Social support in terms of companionship could facilitate a patient's adherence to physical activity (Neblett, Chia, Abdullah, \& Ablah, 2019). Poor DSC was reported in regards to medication and diet due to the absence of emotional support from HCP, affection from family members and tangible support (i.e. financial) (Rashid, Zuhra, \& Tan, 2018). This was supported by Othman and Khurshid (2014) on good financial status resulting in better awareness, and Karimy et al. (2018) on higher awareness in marriage with addition to demographic variables (gender, education level and duration of disease). Involvement of family members were also found to be supporting in patients' medicine intake (Al Hamid, Ghaleb, Aljadhey, \& Aslanpour, 2017). While a good relationship with HCP played a vital role in motivation (Gao et al., 2013), and patients perceived frequent follow-ups as beneficial for their treatment (Mikhael, Hassali, Hussain, \& Shawky, 2019). Other demographic issues were also associated with a patient's motivation to DSC. Evidence from Ardeňa et al. (2010), indicates that the education attainment of the rural population among Filipinos contribute to a positive attitude in DSC.

Several factors were found contributed to a patient's demotivation on DSC. These factors include a negative relationship with HCP in terms of waiting time for appointments with physicians (Mikhael et al., 2019), doctors' limited time in dealing with patients' inquiries (Neblett et al., 2019), accessibility to health facility (Ardeňa et al., 2010) and lack of diabetes education facilities in the clinics (Mukhopadhyay et al., 2010). It was also found that well-educated diabetic patients are resistant to behaviour change, unthoughtful and overconfident (Gautam, Bhatta, \& Aryal, 2015).

Several studies conducted in European countries demonstrated different patterns of depressionemployment relation for women and men with T2DM. Women ages between 51 to 65 years old who still working were more likely to have depression compared to retirees (Brandão \& Cardoso, 2020). However no significant finding was found among men. Depression among women workers may be associated to burden of having diabetes while maintaining a career which might affects their daily life. Likewise, responsibility to family and children may afflict women in managing diabetes (Aliaga, 2006; Graham, Thomson \& Bambra, 2018).

Patients' poor perspectives on DSC were also associated with a negative perception of the meaning of life (Solanki et al., 2017). A study by Elmira, Banks and Joshy (2018) showed that the prevalence of psychological distress was twice higher among diabetic patients especially those with severe disability. Mikhael et al. (2019) also highlighted diabetic patients' inability to cope with the disease resulted from their incapability in managing stress. Recently, a study in Malaysia discovered that a diabetic patient 
with complication is more likely to have high depression (Radzi, Draman, Yusoff, \& Muhamad, 2019). However, in some countries, stress management among diabetic patients may be aggravated by certain culture traits. For example, Chinese patients was less expressive as behaviour of seeking help from others, especially a psychiatrist, is considered shameful (Wu et al., 2011).

\section{Behaviour}

In this review, several potential factors that might contribute to behavioural compliance towards DSC were identified. It was found that culture, religion and perceived behavioural barriers emerged as factors affecting dietary intake as shown in studies in Iraq (Mikhael et al., 2019), Indonesia (Primanda, Kep, Kritpracha, \& Thaniwattananon, 2011), Saudi Arabia (Al Hamid et al., 2017) and Malaysia (Neblett et al., 2019). For instance, diet practices in Indonesia were embedded in cultural activities such as during social gatherings, the act of refusing the food given was considered disrespectful. In Malaysia, social habits such as eating out and home-prepared foods affected patients' dietary intake. While in Saudi Arabia, patients' non-adherence to medication was influenced by religious practices, such as pilgrimage (Hajj/Umrah) and fasting. Thus, to fulfil the religious obligations during fasting month, Muslim patients need to alter their diabetic patients' medication. The dietary pattern in the United States is similar to the Mediterranean-style which showed an association with an overall lower risk of diabetes (O'Connor, Hu, Steffen, Selvin, \& Rebholz, 2020).

This review identified several potential factors related to physical activity and DSC. In previous study, more males were involved in physical activities compared to females, particularly in developing countries such as Bangladesh and Arab countries. In some countries, females were mostly staying at home as housewives (Alshayban \& Joseph, 2020; Al-Aboudi, Hassali, \& Shafie, 2016). Other demographic factors that contributed to poor behaviour, such as level of education, marital status and duration of disease (Al-Maskari et al., 2013). Apart from that, environmental factors (hot climate and dirty roads) and geographic factors affected a patient's behaviour on complying physical activity. In Iraq, the extreme hot weather and dangerous sectional violence (war) restricted a patient's daily activity (Mikhael et al., 2019). Insufficient access to DSC was reported in rural areas of low-income countries (Price et al., 2018).

Financial constraints such as occupation and income variables were frequently emphasised in previous literatures (Saleh et al., 2012a; Kishore, Kohli, Gupta, Kumar, \& Sharma, 2015). Financial constraint was associated with adherence to SMBG (G. B. Rathod et al., 2014). A majority of patients from lowincome family unable to afford a glucometer. Moreover, the test strips are expensive hence it is impossible to practice diabetes self-care frequently (Tohid et al., 2019). Additionally, low-income among diabetic patients became a barrier to afford healthy food resulting in poor management of dietary behaviours (Primanda et al., 2011) and other diabetes medication such as insulin (Herkert et al., 2019).

This review has highlighted a complex interaction between information, motivation and behavioural factors in influencing DSC. A diabetic patient may change their lifestyles if they are facing the adverse effects of their behaviour. Speight, Skinner, Rose, Scibilia, \& Boulton (2020) addressed this issue which acknowledges the roles of intrinsic motivation such as capacity, ability and the opportunity in motivating people to sustain their behavioural change. Thus, the authors argue that fear-based decisions that were embedded in the intervention strategies are less likely to enhance behavioural change unless they also emphasised on intrinsic motivation.

\section{Conclusion}

This review provides an overview of the evidence on the importance of identifying IMB in relations with DSC. Information is among the important factors that facilitate DSC in terms of increasing knowledge or awareness through comprehensive health communication strategies. This review also identified the importance of motivation and the impact of demotivation in patients towards diabetic patients coping skills. Another important factor identified is the behavioural compliance towards DSC 
Malaysian Journal of Social Sciences and Humanities (MJSSH), Volume 5, Issue 8, (page 39 - 47), 2020

DOI: https://doi.org/10.47405/mjssh.v5i8.460

and how it is influenced by certain culture traits and external factors. Thus, the outcome of this review could provide a better understanding of IMB and DSC in diabetes care and management.

\section{Acknowledgement}

We would like to thank the Director General of Health Malaysia for his permission to publish this article.

This study was fully funded by Ministry of Health Malaysia, project code NMRR-19-862-46635. This study obtained ethical clearance from the Ministry of Health Malaysia - KKM/NIHSEC/P19-1453(7) (August $8^{\text {th }}, 2019$ ).

\section{References}

Ahmad, B., Ramadas, A., Fatt, Q. K., \& Zain, A. Z. M. (2014). A pilot study: The development of a culturally tailored Malaysian Diabetes Education Module (MY-DEMO) based on the Health Belief Model. BMC Endocrine Disorders, 14(1), 31. https://doi.org/10.1186/1472-6823-14-31

Ajzen, I., \& Driver, B. L. (1991). Prediction of leisure participation from behavioural, normative, and control beliefs: An application of the theory of planned behaviour. Leisure Sciences, 13(3), 185204. https://doi.org/10.1080/01490409109513137

Al-Aboudi, I. S., Hassali, M. A., \& Shafie, A. A. (2016). Knowledge, attitudes, and quality of life of type 2 diabetes patients in Riyadh, Saudi Arabia. Journal of Pharmacy and Bioallied Sciences, 8(3), 195-202. https://doi.org/10.4103/0975-7406.171683

Al-Maskari, F., El-Sadig, M., Al-Kaabi, J. M., Afandi, B., Nagelkerke, N., \& Yeatts, K. B. (2013). Knowledge, attitude and practices of diabetic patients in the United Arab Emirates. PLoS ONE, 8(1), 1-8. https://doi.org/10.1371/journal.pone.0052857

Al Hamid, A. M., Ghaleb, M., Aljadhey, H., \& Aslanpour, Z. (2017). Factors contributing to medicine-related problems in adult patients with diabetes and/or cardiovascular diseases in Saudi Arabia: a qualitative study. BMJ Open, 7(11), 1-8.

Aliaga, C. (2006). How is the time of women and men distributed in Europe. Eurostat.

Aljasem, L. I., Peyrot, M., Wissow, L., \& Rubin, R. R. (2001). The impact of barriers and self-efficacy on self-care behaviours in type 2 diabetes. The Diabetes Educator, 27(3), 393-404.

Alshayban, D., \& Joseph, R. (2020). Health-related quality of life among patients with type 2 diabetes mellitus in Eastern Province, Saudi Arabia: A cross-sectional study. PLoS ONE, 15(1), 1-12. https://doi.org/10.1371/journal.pone.0227573

American Diabetes Association. (2013). Standards of medical care in diabetes-2013. Diabetes Care, 36(Supplement 1), S11-S66. https://doi.org/10.2337/dc13-S011

Ardeňa, G. J. R. A., Paz-Pacheco, E., Jimeno, C. A., Lantion-Ang, F. L., Paterno, E., \& Juban, N. (2010). Knowledge, attitudes and practices of persons with type 2 diabetes in a rural community: phase I of the community-based Diabetes Self-Management Education (DSME) Program in San Juan, Batangas, Philippines. Diabetes Research and Clinical Practice, 90(2), 160-166. https://doi.org/10.1016/j.diabres.2010.08.003

Bains, S. S., \& Egede, L. E. (2011). Associations between health literacy, diabetes knowledge, selfcare behaviours, and glycemic control in a low income population with type 2 diabetes. Diabetes Technology and Therapeutics, 13(3), 335-341. https://doi.org/10.1089/dia.2010.0160

Bandura, A. (1986). Social foundations of thought and action. Englewood Cliffs, NJ, 1986, 23-28.

Bartlett, E. E. (1982). Behavioural diagnosis: a practical approach to patient education. Patient Counselling and Health Education, 4(1), 29-35.

Brandão, M. P., \& Cardoso, M. F. (2020). Associations between depressive symptoms and being employed or retired in older adults with type 2 diabetes. Primary Care Diabetes.

Burke, S. D., Sherr, D., \& Lipman, R. D. (2014). Partnering with diabetes educators to improve patient outcomes. Diabetes, Metabolic Syndrome and Obesity: Targets and Therapy, 7, 45-53. 
Carver, C.S., \& Scheier, M.F. (1998). On the self-regulation of behaviour. Retrieved from https://www.semanticscholar.org/paper/On-the-Self-Regulation-of-Behaviour-Carver Scheier/b8b92cbf8c60d350e62825284173c08d5ef6227b

Chatterjee, S., Khunti, K., \& Davies, M. J. (2017). Type 2 diabetes. The Lancet, 389(10085), 22392251. https://doi.org/10.1016/S0140-6736(17)30058-2

Duke, D. C., Barry, S., Wagner, D. V., Speight, J., Choudhary, P., \& Harris, M. A. (2018). Distal technologies and type 1 diabetes management. The Lancet Diabetes \& Endocrinology, 6(2), 143-156. https://doi.org/10.1016/S2213-8587(17)30260-7

Elmira, E., Banks, E., \& Joshy, G. (2018). To what extent is the elevated risk of psychological distress in people with diabetes accounted for by physical disability? Findings from a large populationbased study. BMJ Open, 8(8), 1-7. https://doi.org/10.1136/bmjopen-2018-022767

Fishbein, M. (2008). A reasoned action approach to health promotion. Medical Decision Making, 28(6), 834-844. https://doi.org/10.1177/0272989X08326092

Gao, J., Wang, J., Zheng, P., Haardörfer, R., Kegler, M. C., Zhu, Y., \& Fu, H. (2013). Effects of selfcare, self-efficacy, social support on glycemic control in adults with type 2. BMC Family Practice, (1), 66. https://doi.org/10.1186/1471-2296-14-66

Gautam, A., Bhatta, D. N., \& Aryal, R. U. (2015). Diabetes related health knowledge, attitude and practice among diabetic patients in Nepal. BMC Endocrine Disorders, 15(1), 25.

Gillespie, N. D., \& Lenz, T. L. (2011). Implementation of a tool to modify behaviour in a chronic disease management program. Advances in Preventive Medicine, 2011, 1-5.

Graham, E. A., Thomson, K. H., \& Bambra, C. L. (2018). The association between diabetes and depressive symptoms varies by quality of diabetes care across Europe. European Journal of Public Health, 28(5), 872-878.

Hawal, N. P., Shivaswamy, M. S., Kambar, S., Patil, S., \& Hiremath, M. B. (2012). Knowledge, attitude and behaviour regarding self-care practices among type 2 diabetes mellitus patients residing in an urban area of South India. International Multidisciplinary Research Journal, 2(12), 31-35.

Herkert, D., Vijayakumar, P., Luo, J., Schwartz, J. I., Rabin, T. L., Defilippo, E., \& Lipska, K. J. (2019). Cost-related insulin underuse among patients with diabetes. JAMA Internal Medicine, 179(1), 112-114. https://doi.org/10.1001/jamainternmed.2018.5008

Hussein, Z., Taher, S. W., Singh, H. K.G., \& Swee, W.C.S. (2015). Diabetes care in Malaysia: problems, new models, and solutions. Annals of Global Health, 81(6), 851-862.

Institute for Public Health (2019). National Health and Morbidity Survey 2019 (NHMS 2019). Vol. I: Non-communicable diseases, healthcare demand, and health literacy. Ministry of Health Malaysia (MOH)

International Diabetes Federation (IDF) (2020, June 23). Available at: idf.org/our-network/regionsmembers/western-pacific/members/108-malaysia.html (Accessed on 23rd June 2020)

Istepanian, R. S. (2015). Mobile applications for diabetes management: efficacy issues and regulatory challenges. The Lancet Diabetes \& Endocrinology, 3(12), 921-923.

Islam, S. M. S., Niessen, L. W., Seissler, J., Ferrari, U., Biswas, T., Islam, A., \& Lechner, A. (2015). Diabetes knowledge and glycemic control among patients with type 2 diabetes in Bangladesh. SpringerPlus, 4(1). https://doi.org/10.1186/s40064-015-1103-7

Janz, N.K., \& Becker, M. H. (1984). The health belief model. A decade later. Health Education Quarterly, 11(1), 1-47.

Karimy, M., Koohestani, H. R., \& Araban, M. (2018). The association between attitude, self-efficacy, and social support and adherence to diabetes self-care behaviour. Diabetology \& Metabolic Syndrome, 10(1), 1-6. https://doi.org/10.1186/s13098-018-0386-6

Kishore, J., Kohli, C., Gupta, N., Kumar, N., \& Sharma, P. (2015). Awareness, practices and treatment seeking behaviour of type 2 diabetes mellitus patients in Delhi. Annals of Medical and Health Sciences Research, 5(4), 266. https://doi.org/10.4103/2141-9248.160184

Kueh, Y. C., \& Kuan, G. (2018). Psychometric Properties of Malay Version of Summary of Diabetes Self-Care Activities Measures among the Malay adults with Type 2 Diabetes Mellitus in Kelantan, Malaysia. Austin Diabetes Res, 3(1), 1017.

Lalazaryan, A., \& Zare-Farashbandi, F. (2014). A Review of models and theories of health information seeking behaviour. International Journal of Health System and Disaster Management, 2(4), 193. https://doi.org/10.4103/2347-9019.144371 
Mikhael, E. M., Hassali, M. A., Hussain, S. A., \& Shawky, N. (2019). Self-management knowledge and practice of type 2 diabetes mellitus patients in Baghdad, Iraq: a qualitative study. Diabetes, Metabolic Syndrome and Obesity: Targets and Therapy, 12, 1.

Mohammadi, S., Karim, N. A., Talib, R. A., \& Amani, R. (2015). Knowledge, attitude and practices on diabetes among type 2 diabetic patients in Iran: a cross-sectional study. Science, 3(4), 520-4.

Mukhopadhyay, P., Paul, B., Das, D., Sengupta, N., \& Majumder, R. (2010). Perceptions and practices of type 2 diabetics: A cross-sectional study in a tertiary care hospital in Kolkata. International Journal of Diabetes in Developing Countries, 30(3), 143-149.

Nagar, V., Prasad, P., Mitra, A., Kale, S., Yadav, K., \& Shukla, M. (2018). Assessment of knowledge, attitude and practice about diabetes among diabetic patients of tertiary care centre in central India. International Journal of Community Medicine and Public Health, 5(9), 4065.

Nazir, S. U. R., Hassali, M. A., Saleem, F., Bashir, S., \& Aljadhey, H. (2016). Disease related knowledge, medication adherence and glycaemic control among patients with type 2 diabetes mellitus in Pakistan. Primary Care Diabetes, 10(2), 136-141.

Neblett, R. S., Chia, Y. C., Abdullah, N., \& Ablah, E. (2019). Goals, beliefs, knowledge, and barriers for diabetes self-care in a multi-ethnic population in Malaysia: A qualitative study. Medical Journal of Malaysia, 74(6), 483-491.

O’Connor, L. E., Hu, E. A., Steffen, L. M., Selvin, E., \& Rebholz, C. M. (2020). Adherence to a Mediterranean-style eating pattern and risk of diabetes in a US prospective cohort study. Nutrition \& Diabetes, 10(1), 1-9.

Othman, S. M., \& Khurshid, T.K. (2014). Knowledge and practice about diabetes among adult diabetic patients in Erbil, Iraq. Zanco Journal of Medical Sciences, 18(1), 659-666.

Tohid, H., Papo, M., Ahmad, S., Sumeh, A. S., Jamil, T. R., \& Hamzah, Z. (2019). Self-care activities among patients with Type 2 Diabetes Mellitus in Penampang, Sabah and its association with depression, anxiety and stress. Malaysian Journal of Public Health Medicine, 19(1), 117-125.

Peyrot, M., \& Rubin, R. R. (2007). Behavioural and psychosocial interventions in diabetes. Diabetes Care, 30(10), 2433-2440. https://doi.org/10.2337/dc07-1222.

Price, A. J., Crampin, A. C., Amberbir, A., Kayuni-Chihana, N., Musicha, C., Tafatatha, T., ... \& Nyirenda, M. (2018). Prevalence of obesity, hypertension, and diabetes, and cascade of care in sub-Saharan Africa: a cross-sectional, population-based study in rural and urban Malawi. The Lancet Diabetes \& Endocrinology, 6(3), 208-222.

Primanda, Y., Kep, S., Kritpracha, C., \& Thaniwattananon, P. (2011). Dietary behaviours among patients with Type 2 Diabetes mellitus in Yogyakarta, Indonesia. Nurse Media Journal of Nursing, 1(2), 211-223.

Polonsky, K. S. (2012). The past 200 years in diabetes. New England Journal of Medicine, 367(14), 1332-1340. https://doi.org/10.1056/NEJMra1110560

Radzi, A. M., Draman, N., Yusoff, S. S. M., \& Muhamad, R. (2019). Depression and potential risk factors among the elderly with Type 2 Diabetes Mellitus in Kedah, Malaysia. Medical Journal of Malaysia, 74(2), 103-108.

Rahaman, K. S., Majdzadeh, R., Naieni, K. H., \& Raza, O. (2017). Knowledge, attitude and practices (KAP) regarding chronic complications of diabetes among patients with type 2 diabetes in Dhaka. International Journal of Endocrinology and Metabolism, 15(3).

Rashid, A. A., Zuhra, H., \& Tan, C. E. (2018). Social support, self-efficacy and their correlation among patients with Type 2 Diabetes Mellitus: A primary care perspective. The Medical Journal of Malaysia, 73(4), 197-201.

Rathod, G. B., Rathod, S., Parmar, P., \& Parikh., A. (2014). Study of knowledge, attitude and practice of general population of Waghodia towards Diabetes Mellitus. International Journal of Current Research and Review, 6(1), 63-68.

Saleh, F., Mumu, S. J., Ara, F., Ali, L., Hossain, S., \& Ahmed, K. R. (2012a). Knowledge, attitude and practice of type 2 diabetic patients regarding obesity: Study in a tertiary care hospital in Bangladesh. Journal of Public Health in Africa, 3(1), 29-32.

Saleh, F., Mumu, S. J., Ara, F., Begum, H. A., \& Ali, L. (2012b). Knowledge and self-care practices regarding diabetes among newly diagnosed type 2 diabetics in Bangladesh: A cross-sectional study. BMC Public Health, 12(1), 1112. https://doi.org/10.1186/1471-2458-12-1112

Sathish, T. (2019). Diabetes prevention and lifestyle intervention in resource-limited settings. The Lancet Diabetes \& Endocrinology, 7(3), 165-167. 
DOI: https://doi.org/10.47405/mjssh.v5i8.460

Shrestha, N., Yadav, S. B., Joshi, A. M., Patel, B. D. P., Shrestha, J., \& Bharkher, D. L. (2015). Diabetes knowledge and associated factors among diabetes patients in central Nepal. International Journal of Collaborative Research on Internal Medicine \& Public Health, 7(5), $82-91$.

Solanki, J. D., Sheth, N. S., Shah, C. J., \& Mehta, H. B. (2017). Knowledge, attitude, and practice of urban Gujarati type 2 diabetics: Prevalence and impact on disease control. Journal of Education and Health Promotion, 6(35), 1-6. https://doi.org/10.4103/jehp.jehp

Speight, J., Skinner, T. C., Rose, K. J., Scibilia, R., \& Boulton, A. J. (2020). Oh sugar! How diabetes campaigns can be damaging to the cause they aim to serve. The Lancet Diabetes \& Endocrinology, 8(7), 566-567. https://doi.org/10.1016/S2213-8587(20)30190-X

Upadhyay, D. K., Izham, M., Alurkar, V. M., Mishra, P., \& Palaian, S. (2012). Evaluation of knowledge, attitude and practice of newly diagnosed diabetes patients-a baseline study from Nepal. International Journal of Pharmacy Teaching \& Practices, 3(2), 245-252.

World Health Organization. (2016). Global Report on Diabetes.

Wu, S. F. V., Huang, Y. C., Liang, S. Y., Wang, T. J., Lee, M. C., \& Tung, H. H. (2011). Relationships among depression, anxiety, self-care behaviour and diabetes education difficulties in patients with type-2 diabetes: a cross-sectional questionnaire survey. International Journal of Nursing Studies, 48(11), 1376-1383. https://doi.org/10.1016/j.ijnurstu.2011.04.008

Zareban, I., Karimy, M., Niknami, S., Haidarnia, A., \& Rakhshani, F. (2014). The effect of self-care education program on reducing HbA1c levels in patients with type 2 diabetes. Journal of Education and Health Promotion, 3. https://doi.org/10.4103/2277-9531.145935 